\title{
International Students' Linguistic Awareness of Malaysian English and its Impact on Intercultural Communication Effectiveness
}

\author{
Shadi Khojastehrad (Corresponding author) \\ Department of English, Faculty of Modern Languages and Communication, Universiti Putra Malaysia \\ E-mail: khojastehrad.shadi@gmail.com \\ Madina Sattarova \\ Department of English, Faculty of Modern Languages and Communication, Universiti Putra Malaysia \\ E-mail: madina.sattarova@yahoo.com
}

Doi:10.7575/aiac.alls.v.6n.5p.250

URL: http://dx.doi.org/10.7575/aiac.alls.v.6n.5p.250
Received: 03/06/2015

Accepted: 15/08/2015

\begin{abstract}
With the rapid development of communication and transportation technology, globalization has brought people of diverse cultures, ethnicities, geographies, and religions together. English is now the primary lingua franca, which is used to communicate with speakers of different native languages throughout the world. However, today the world is faced with the rapid emergence of many new Englishes with their own specific features and markers. Thus, learning only standard British and American English and lack of familiarity with the other English language varieties causes misperception, negative attitude, and communication failure with the speakers of those certain varieties. The present research is aimed at exploring how much international students are aware of Malaysian English and whether the level of their linguistic awareness affects their intercultural communication effectiveness with Malaysians. The data was collected from a survey administered to 372 international students who were studying at three selected public and private universities in Malaysia. Three focus group discussions followed up the survey to triangulate the quantitative findings. The findings suggest that a majority of the students appear to be moderately communicating ineffectively with Malaysians, and their lack of familiarity with Malaysian English makes them to perceive it as a wrong deviated form of English. The results also reveal that the respondents' misperception of Malaysian English influences their intercultural communication effectiveness negatively.
\end{abstract}

Keywords: Malaysian English, Linguistic Awareness, Intercultural Communication Effectiveness, International Students, World Englishes

\section{Introduction}

English holds the status of native language in countries like America, Britain, Australia and New Zealand known as native-speaker countries. On the other hand, it is used in a non-native linguistic ecology (most often multilingual contexts) in those countries which were either formerly colonized by America and Britain and now belong to the New Commonwealth of Nations or are independent nations, such as India, Malaysia, Africa, Singapore and Hong Kong (English is a used as the second language in these contexts), or in those countries which were not colonized but English was used as a foreign language, like Russia, Germany, Poland, Belgium, China, Egypt and Japan.

Despite the rapid emergence of New Englishes worldwide, the international Standard English (SE) is still the first model to follow in many countries. SE represents a variety which is commonly recognized to have prestigious and intelligible vocabulary, grammar and orthography (Crystal, 1995). It is identified as a particular dialect of English, which is not localized and does not have significant variation, and well known as the appropriate educational target in teaching English (Strevens, 1985).

Today, English is highly influenced by the rapid trend of globalisation and its associated processes. According to McKay (2002, p. 12) English used as an international language for a global purpose differs from the type used for local purposes. She points out that English as an international language is used for communication between countries, whereas for local purposes, it is used for communication within multilingual societies. In fact, in a process which Sharifian (forthcoming) called it glocalisation of English, it is believed that the very global spread of English involves localisation of the language too.

\subsection{Linguistic Awareness}

The term Linguistic Awareness refers to the ability of conscious reflection on certain features of primary linguistic activities like listening and speaking. From a psychological perspective, linguistic awareness represents the ability to change attention from the content to form (Magnusson and Naucle'r, 1993). In an interesting description of linguistic 
awareness, it was defined metaphorically like a glass window (Cazden, 1976); where attention is switched from what is seen through the window to the glass itself. According to Lyster (2001), 'Linguistic Awareness refers to the awareness of all linguistic levels (phonology, morphology, ortograpghy, syntax, and semantics), like segmentation of sentences to words; words to sound parts(rhyme and onset), syllables to phonemes, identifying morphemes in words; and finally judgment of grammatical correctness.

\subsection{Intercultural Communication}

Intercultural communication occurs when two or more individuals with different cultural background interact. This process is rarely smooth and problem free. In most situations, intercultural interactants do not share the same language.

The central idea of the Sapir-Whorf hypothesis is that language functions, not simply as a device for reporting experience, but also and more significantly as a way of defining experience for its speakers (Sapir, 1931).

However, as Berger and Calabrese (1975) discussed, the lack of information about one another during initial interactions leads to the increase of the situational uncertainty or ambiguity, which in turn provokes feelings of anxiety or apprehension of interactants. The uncertainty level is especially high in intercultural communication because the novelty and unfamiliarity caused by the cultural differences is high (Gudykunst, 1995). The feeling of anxiety in an uncertain situation usually jeopardizes effective communication in an intercultural context (Gudykunst, 2005; Kassing, 1997; Kim, 1988).

\subsection{Link between LA and ICE}

The labels we use for our English such as 'my English' and 'your English' represent that it is not the sociolinguistic norms which determines the appropriateness of a linguistic behaviour but it is the functionality of the language which seems to be the principal criterion to evaluate one's given interaction inter-subjectively. If a certain cultural norm does not predominate the others, people would accept differences easily and they try to understand each other empathically. Here is exactly where the accommodation strategy is used to make semantic adjustments for the negotiation of meaning. The ability to use accommodation strategy is 'adjustability', and it is claimed that adjustability is the basis of functionality. Thus, the linguistic awareness of language varieties helps to understand the differences and to apply effective accommodation strategies in order to develop effective intercultural communication with individuals from different countries.

\section{Literature Review}

\subsection{Malaysian English}

Malaysian English is an indigenized variety of English which is geographically spread out and socially defined throughout Malaysia. Malaysian English is spoken by the speech community, as defined by Gumperz (1972), and Labov (1972), the "speech fellowship" (Firth 1957; Kachru 1982) of Malaysians speakers of English including the English-educated as well as the marginally proficient speakers. It is spoken in a continuum of variation starting from the most Standard form (Acrolect) to the most Colloquial form (Basilect), with a moderately localized version (Mesolect) between these the two extremes.

In fact, Malaysian English is a complex language spoken by Malaysians from different educational, ethnic, and geographical backgrounds with different levels of proficiency. There is a minority group in Malaysia who speak English as their first language (Crystal 1999); while for the rest it might range from a dominant language at home to never used at home. However, the extent to which English is used in daily communication depends on some other factors like geographical location and career too (Pillai et al, 2010). Actually, the acculturation of English is like using English as a localized form of communication in Malaysia (Morais, 1994; Nair-Venugopal, 1997; Anie, 1998; cited in NairVenugopal, 2006: p3).

Some typical features of Malaysian English identified by Baskaran (1987) for the syntactical features are like omitting the copula and articles, lack of agreement between subject and pronoun, pluralisation of mass nouns, and frequent use of the tag questions as the common syntactical markers of ME. On the other hand, phonological markers of ME have distinguished this variety from the other variations too. Some stances of phonological makers of ME are consonant reduction from three to two or two to one, frequent deletion of final consonants for agent or a glottal stop replacement, various pronunciation of "th" particularly in initial position, long vowel shortening, and short vowel lengthening, and diphthongs reduction (monopthongisation). These features of ME might confuse the interlocutors whether from native on non-native contexts who are not familiar with this English variety of English

\subsection{Previous Studies on Linguistic Awareness}

According to Webb et al. (2014), teachers play a crucial role in making the students aware of the linguistic diversities of non-native varieties of English all over the world, and teach them how to make the move smoothly when they plan to stay in a foreign country.

In an ethnographic research carried out by Kitchen (2014) among Koreans at 3 selected schools in Auckland, it was found out that communication is subject to failure when individuals at a new context deliberately tease out different cultures, communication practices, and more particularly the English language varieties they speak. These findings were also supported by Kanno (2003) who showed that once immigrant families move to a different country with new social, cultural, and linguistic background, they might not be able to cope with the differences in case they are not familiar with. However, this is not only to blame the immigrant families, the host nationals should get familiar with the diversity 
of cultures and languages worldwide too in order to be more welcoming to the variations and develop effective intercultural communication with the other community members too.

Similarly, Alavi et al. (2011) carried out a study to identify the most prevalent problems among international students in Malaysia. They found that Malaysian lecturers' accented English was one of the major problems among international students in classes.

In a similar research, Malaklolunthu \& Selan (2011) studied the international students' adjustment issues in Malaysia. They found that the most problematic issues faced by the international students in Malaysia are academic adjustments, religion adjustments, personal adjustments, social adjustments, financial adjustments, and finally language adjustments.

According to Siegler (1985), students who are familiar with the host nationals' linguistic background, have a strong conceptual framework to understand the differences, and adjust to the new context easily. This was supported by Brunton et al.(2014) who showed that language was the biggest barrier in communication with the host nationals among 196 international students at a public university in New Zealand (Brunton \& Jeffrey, 2014).

\subsection{Previous studies on Intercultural Communication Effectiveness (ICE)}

It has been shown that local friends can be of considerable help to international students in developing effective social integration, better intercultural communication, lowering stress (Redmond \& Bunyi, 1993) and coping with fewer psychological problems to adjust (Ward \& Searle, 1991). In another study by Spencer-Oatey and Xiong's (2006) on Chinese students in Britain, it was revealed that despite the students' emphasis on socialization, intercultural adjustment and communication with the locals, intercultural interaction was found the most challenging area. Similar problem was also studied by Wilson (2011) who found that the problems of "struggle and strive" are one of the most common problems experienced by the international students, which can be overcome by increasing flexibility and adaptability particularly in a multicultural environment (Bodycott \& Lai, 2012).

However, Spencer-Oatey and Xiong (2006) found out that despite the high level of adaptability among Chinese students, they are mostly struggling with communication problems with non-Chinese; though the linguistic aspect was not studied. Age has been also reported to be negatively correlated with adjustment (Stevens, 1999); but length of residence has been found to be facilitating international students' adjustment to the differences in host countries (Cortes, Rogler \& Malgady, 1994). In addition, mental health (Ouarasse \& Van De Vijver, 2005); educational level, and learning the language of the host country (cited in Long et al., 2009: p2) have been identified to be contributing to socio-cultural and psychological adaptation while living in a foreign country (Jayasuriya, Sang \& Fielding, 1992).

Bochner, McLeod and Lin (1977) also argued that international students come across many different on-campus networks which serve them various sociocultural and psychological functions. For instance, international students in English speaking countries tend to turn to local students to improve their language skills and benefit from their help in academic difficulties. However, they showed to be more willing to communicate with the co-nationals for emotional support. Studies have shown that co-national friendship increases students' global self-esteem (Al-Sharideh \& Goe, 1998), strengthen their cultural identity, support them emotionally (Maundeni, 2001), and sharing experience would help them to deal more efficiently with the acculturation stresses. Despite all these benefits, different personalities and reactions to intercultural adaptation might also lead to different intercultural communication outcomes (Lin, 2008). For instance, Kim (2001) revealed that co-national groups might sometimes heighten cross cultural problems which can consequently affect intercultural communication effectiveness negatively. Ward and Searle (1991) showed that high level of co-national interpersonal communication might tense up cultural identity and discourage students to adapt with the host culture and communicate with the locals.

\section{Methods}

\subsection{Research Design}

The researcher adopted a mixed method (quantitative-qualitative) research design to investigate the extent to which international students are aware of Malaysian English as a non-native variety, how effective they are in communication with Malaysians, and finally the effect of their linguistic awareness on their intercultural communication effectiveness. Thus, an interdisciplinary theoretical framework linking Schema theory from the Linguistic school, and AnxietyUncertainty Management theory (AUM) from the Communication school was adapted to analyse the findings and investigate the correlation between Linguistic Awareness and Intercultural Communication Effectiveness. The research was conducted in 3 phases: (1) Focus Group Discussion (FGD.1), (2) Survey, and (3) Autobiography and Focus Group Discussion (FGD.2) (Figure 3.1)

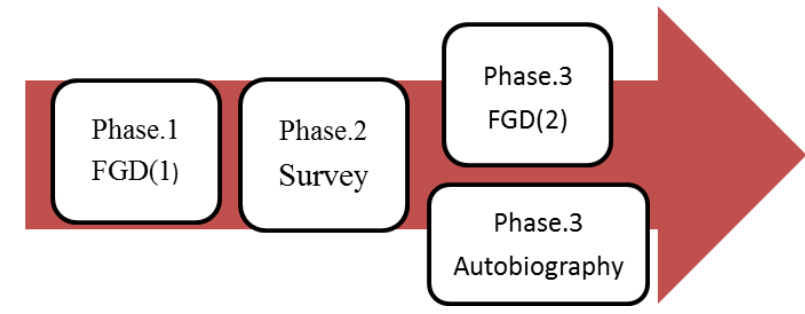

Figure 3.1 Research Flow 


\subsection{Sampling Procedure}

Purposive sampling procedure was used to invite international students to participate in the survey. Participants for the focus group discussions and autobiographies were invited from the sampling pool of the quantitative phase of the study. The participants were screened based on the following criteria: nationality, university program, and employment. The rationale for determining these elements as screening factors is as follows:

- University Program: The respondents were screened to check if they were still pursuing English programs, they were proficient enough to be able to communicate in English easily and make fair judgement about communication effectiveness with the other communities.

- Employment: The respondents were screened to check if they were working in Malaysia, because the employed participants would have been socializing with the locals so often that they would not feel any special difficulty to communicate effectively with the locals. Thus the data would lose validity as confounding variables were not controlled.

- Nationality: The respondents were screened to be from diverse nationalities excluding countries where they could also speak like Bahasa Malay like Indonesians whose mother tongue shares a lot of common linguistic features with Malay. Thus, they did not need to speak English with the locals, except a few cases when they had to.

\subsection{Participants}

The participants were from diverse nationalities, and were involved in different undergraduate, graduate and postgraduate programs at the three universities. They were all required to obtain an IELTS academic score of not less than 6 to begin university courses. A total of 372 International students participated in this study. The demographics of the respondents are presented in table 3.1.

Table 3.1 Demographics of the Respondents

\begin{tabular}{lll}
\hline Item & Frequency & Percentage \\
\hline Gender & 291 & 78.2 \\
$\quad$ Male & 81 & 21.8 \\
$\quad$ Female & 82 & 22.0 \\
English Language Background & 290 & 78 \\
$\quad$ ESL & & \\
EFL & 17 & 4.6 \\
Age $\quad 195$ & 52.4 \\
$\quad$ Less than 20 & 135 & 36.3 \\
20-30 years old & 24 & 6.5 \\
31-40 years old & & \\
41-50 years old & 91 & 24.5 \\
Educational Level & 169 & 45.4 \\
Bachelor & 103 & 27.7 \\
Master & 2 & .5 \\
PhD & & \\
Post.Doc & 101 & 27.2 \\
Field of Study & 271 & 72.8 \\
Linguistics & & \\
Non-Linguistics & 165 & 44.4 \\
Length of Stay in Malaysia & 110 & 29.6 \\
Less than a year & 44 & 11.8 \\
1-2 years & 23 & 6.2 \\
3-4 years & 29 & 7.8 \\
4-5 years & & \\
Over 5 years &
\end{tabular}

\subsection{Instrument}

The primary data which could contribute to the construction of the questionnaire was collected from 3 focus group discussions conducted at the first phase of the study. They were recorded, and transcribed verbatim. The interview questions addressed the international students' perception of Malaysian English (ME), perceived differences between Malaysian English and Standard English, and any possible difficulties they faced to interact with Malaysians.

For the second phase of the research which was in a quantitative design, a questionnaire was administered. The first section of the questionnaire consisted of 14 questions about the respondents' demographics, second part addressed the respondents' attitude towards the three main Malaysian English ethnolects (the findings are published in Khojastehrad \& Rafik-Galea (forthcoming), the third section questioned the participants' perception of English varieties worldwide 
with a particular focus on Malaysian English, consisting of 20 items in a 6-point Liker-Scale format. The items were developed based on the most concurrent impressions, and ideas brought up in the Focus Group Discussions. The last section of the questionnaire addressed the participants' intercultural communication effectiveness with Malaysians through a 6-point Likert Scale measurement with 20 items adapted from Castro et al. (2013), Seim (2008), McKenzie(2007), Neuliep \& McCroskey (1997), and Yashima et al. (2004). The third phase of the research was conducted in a qualitative design to triangulate the findings obtained in the second phase. The data was collected through 3 focus group discussions and 19 autobiographies which were aimed to elicit information about the participants' linguistic awareness of Malaysian English and the other non-native varieties of English, the extent to which they were exposed to different varieties of English before, and whether their understanding of Malaysian English could impact on their communication effectiveness with Malaysians.

\subsection{Data Analysis}

The collected data obtained through the 3 phases were analysed by the related soft wares. The quantitative data was passed through SPSS.18, and the qualitative data was analysed by NVivo.8.

\section{Findings}

In order to measure the extent to which the respondents perceived Malaysian English as a variety, a simple descriptive statistics was employed. A summary of the results is provided next. The majority of the respondents (59.4\%) were moderately aware of the variety of Malaysian English, 39.2\% of international students seemed to be highly unaware of this variety, whereas only $1.3 \%$ showed high linguistic awareness of Malaysian English (refer to Table 4.1)

Table 4.1 Level of Linguistic Awareness

\begin{tabular}{lllll}
\hline & & Frequency & Percent & Valid Percent \\
\hline \multirow{3}{*}{ Valid } & $\mathrm{L}$ & 5 & 1.3 & 1.3 \\
\cline { 2 - 5 } & $\mathrm{M}$ & 221 & 59.4 & 59.4 \\
\cline { 2 - 5 } & $\mathrm{H}$ & 146 & 39.2 & 39.2 \\
\cline { 2 - 5 } & Total & 372 & 100.0 & 100.0 \\
\hline
\end{tabular}

\begin{tabular}{|l|}
\hline Abbreviations \\
\hline L: Low \\
M: Moderate \\
H: High \\
\hline
\end{tabular}

The findings for the respondents' linguistic awareness are consistent with Matsuda's (2003) findings. Matsuda found that limited exposure to the varieties of English in the EFL contexts of Japan has led to student confusion and in some cases resistance when exposed to different versions of English. Thus, their linguistic awareness was found low because of lacking familiarity with the other native and non-native varieties of English other than British and American English.

As for the next research objective, international students' intercultural communication effectiveness with Malaysians was measured by a simple descriptive statistics. The results are presented in table 4.2.

Table 4.2 international students' intercultural communication effectiveness with Malaysians

\begin{tabular}{lllll}
\hline & & Frequency & Percent & Valid Percent \\
\hline \multirow{3}{*}{ Valid } & L & 110 & 29.6 & 29.6 \\
\cline { 2 - 5 } & $\mathrm{M}$ & 240 & 64.5 & 64.5 \\
\cline { 2 - 5 } & $\mathrm{H}$ & 22 & 5.9 & 5.9 \\
\cline { 2 - 5 } & Total & 372 & 100.0 & 100.0 \\
\hline
\end{tabular}

As shown in the table above, a majority of the respondents appeared to be moderately communicating ineffectively with Malaysians (64.5\%), whereas only 5.9\% demonstrated a high level of ineffective communication with them.

In order to identify the extent to which international students' linguistic awareness of ME affects their intercultural communicaton effectiveness with Malaysians, a correlational analysis was run on the collected data from the perceptual section of the questionnaire and the intercultural communication part. The analysis was also applied on the co-concepts of ICE to find the strength of the correlation between Schemata(co-concept of Schema theory) and its three underlying co-concepts of Anxiety, Uncertainty, and Mindfulness (co-concepts of Anxiety-UncertaintyManagement theory). A summary of the findings is presented in table 4.3. 


\section{Correlations}

\begin{tabular}{|c|c|c|c|c|c|c|}
\hline & & $\begin{array}{l}\text { Lack of } \\
\text { Linguistic } \\
\text { Awareness }\end{array}$ & $\begin{array}{l}\text { Ineffective } \\
\text { Intercultural } \\
\text { Communication }\end{array}$ & Anxiety & Mindlessness & Uncertainty \\
\hline \multirow{3}{*}{$\begin{array}{l}\text { Lack of Linguistic } \\
\text { Awareness }\end{array}$} & $\begin{array}{l}\text { Pearson } \\
\text { Correlation }\end{array}$ & 1 & $.301^{* *}$ & $.174^{* *}$ & $.214^{* *}$ & $.370^{* * *}$ \\
\hline & $\begin{array}{l}\text { Sig. (2- } \\
\text { tailed) }\end{array}$ & & .000 & .001 & .000 & .000 \\
\hline & $\mathrm{N}$ & 372 & 372 & 372 & 372 & 372 \\
\hline \multirow{3}{*}{$\begin{array}{l}\text { Ineffective } \\
\text { Intercultural } \\
\text { Communication }\end{array}$} & $\begin{array}{l}\text { Pearson } \\
\text { Correlation }\end{array}$ & $.301^{* *}$ & 1 & $.676^{* *}$ & $.630^{* *}$ & $.659^{* *}$ \\
\hline & $\begin{array}{l}\text { Sig. }(2- \\
\text { tailed) }\end{array}$ & .000 & & .000 & .000 & .000 \\
\hline & $\mathrm{N}$ & 372 & 372 & 372 & 372 & 372 \\
\hline \multirow{3}{*}{ Anxiety } & $\begin{array}{l}\text { Pearson } \\
\text { Correlation }\end{array}$ & $.174^{* *}$ & $.676^{* *}$ & 1 & $.345^{* *}$ & $.408^{* *}$ \\
\hline & $\begin{array}{l}\text { Sig. }(2- \\
\text { tailed) }\end{array}$ & .001 & .000 & & .000 & .000 \\
\hline & $\mathrm{N}$ & 372 & 372 & 372 & 372 & 372 \\
\hline \multirow{3}{*}{ Mindlessness } & $\begin{array}{l}\text { Pearson } \\
\text { Correlation }\end{array}$ & $.214^{* *}$ & $.630^{* * *}$ & $.345^{* *}$ & 1 & $.463^{* *}$ \\
\hline & $\begin{array}{l}\text { Sig. (2- } \\
\text { tailed) }\end{array}$ & .000 & .000 & .000 & & .000 \\
\hline & $\mathrm{N}$ & 372 & 372 & 372 & 372 & 372 \\
\hline \multirow{3}{*}{ Uncertainty } & $\begin{array}{l}\text { Pearson } \\
\text { Correlation }\end{array}$ & $.370^{* * *}$ & $.659^{* * *}$ & $.408^{* *}$ & $.463^{* *}$ & 1 \\
\hline & $\begin{array}{l}\text { Sig. (2- } \\
\text { tailed) }\end{array}$ & .000 & .000 & .000 & .000 & \\
\hline & $\mathrm{N}$ & 372 & 372 & 372 & 372 & 372 \\
\hline
\end{tabular}

As shown in table 4.3, lack of linguistic awareness is highly correlated with intercultural communication ineffectiveness, and all 3 co-concepts underlying: anxiety, mindlessness, and uncertainty. Correlations between lack of ineffective linguistic awareness and intercultural communication ineffectiveness, anxiety, mindlessness, and uncertainty showed Pearson coefficients of $0.301,0.174,0.374,0.174,0.214$, and 0.370 respectively. This implies that the less a respondent is linguistically aware of the variety of English spoken by Malaysians, the more uncertain, anxious, and mindless he/she becomes in communicating with the locals, and it consequently influences intercultural communication ineffectiveness to increase. In other words, the results represent that when international students are less aware of Malaysian English, their level of uncertainty, anxiety, and mindlessness increase, which all contribute to intercultural communication break down with Malaysians.

In addition, as it was shown above, ineffective intercultural communication is highly correlated with anxiety with a Pearson correlation coefficient of 0.676 . This indicates that with an increase in anxiety, the level of intercultural communication effectiveness declines sharply too. Similar results can be also noticed in the correlation between intercultural communication effectiveness and uncertainty as shown in table 4.3. As presented in the table above, intercultural communication ineffectiveness is highly correlated with uncertainty with a Pearson correlation coefficient of 0.659 . This result represents a strong, positive correlation between intercultural communication ineffectiveness and uncertainty, which means that once international students' uncertainty increases, the chances to establish effective intercultural communication with the locals decrease accordingly. Based on the findings, uncertainty and mindlessness are highly correlated, with Pearson correlation coefficient of 0.463 , as well as uncertainty and anxiety with Pearson correlation coefficients of 0.408 .

As we can notice in table 4.3, all correlation coefficients are significant at the 0.01 level, due to the p-values less than 0.01 for all coefficients, which represent very strong correlation between all concepts.

Thus, based on the above findings, it is concluded that there is a strong correlation between the lack of linguistic awareness arising from schemata shaped in students' mind for the conventional dichotomy of English nativeness/nonnativeness and intercultural communication effectiveness which is also supported by the qualitative findings obtained from the third phase of the research as presented below. 


\subsection{Findings from the Qualitative Phase}

The qualitative analysis of the Autobiography and Focus Group Discussion transcripts showed very interesting results which supported the findings obtained from the quantitative phase of the study. Figure 4.1 represents a comprehensive model generated by NVivo8 illustrating the relationship between linguistic awareness of Malaysian English and intercultural communication effectiveness with Malaysians based on the thematic analysis of the qualitative data collected from autobiographies and focus group discussions.

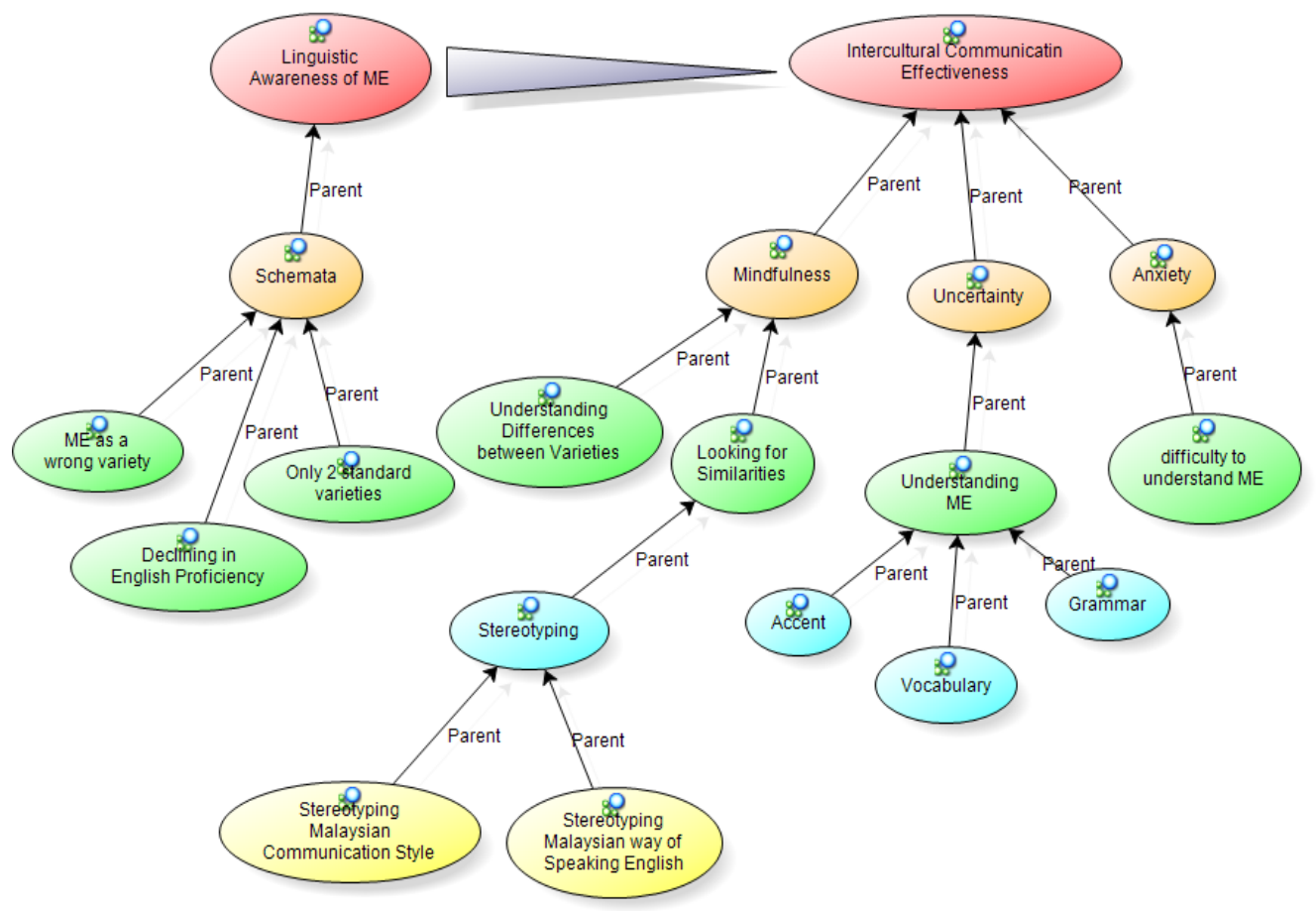

Figure 4.1 Model of Correlation between LA and ICCE

A number of students explained the effect of understanding Malaysian English on their communication effectiveness with the locals as following:

Excerpt 85

“...I'd believe their English is another factor affecting communication with them, because when I don't understand what they say, I prefer to communicate with those who I can understand better. This is a simple rule." (Iranian female)

Excerpt 86

“...I do believe that understanding Malaysian English is very important in communication; because when I face a person when I talk to him or her, he doesn't understand me, he don't have any reaction to what I'm saying, so I don't have any to continue to communicate with him or her so I prefer to talk to anybody else that can understand me." (Somalian female)

As the Iranian and Somalian students claimed, when they do not understand someone's English they tend to withdraw from communication with them and turn to someone whom they understand better.

Excerpt 87

"... it naturally affects communication with them because we need to deal with
them, interact with them according to their level of proficiency then sometimes you
see you don't need to use the grammar instead of pronouncing the whole sentence
you would maybe just reply or answer using only one word which is bad for us as
academic figures because it's supposed to be in academic way I mean in the
academic context even in the ordinary life still using it the same."
(Pakistani female)

The Pakistani student also felt unhappy with the way she has to adjust her English with the localized form of English in Malaysia. She expects her interaction frame to be in academic, standard, and complete forms; however she claims that she has to adjust with the localized form of Malaysian English to sound understandable to Malaysians. 


\section{Excerpt 88}

“..Of course understanding Malaysian English has affected my

communication with them. It was limited previously, but now it has improved a lot. I understand them very well and some of my friends also who recently arrived in Malaysia they couldn't understand when they are... when they talk... for example my friends tell me guy was talking to me in Chinese language? ...then I say no he was talking English, then she asks how you understand him... I said I'm used to it, after a while it becomes normal, so I get good price, I get good discounts, and they help me a lot, even now I have some Malaysian university friends, I communicate with them very well"

(Jordanian female)

In contrast with the other interviewees, the Jordanian student expressed positive ideas about Malaysian English, and how well she has adjusted to this variety of English. She feels totally satisfied with the impact of her adjustment on her wellbeing in Malaysia and effective communication with the locals. She claimed that after some time, she got used to Malaysian English and now she understands it absolutely well.

It can be noted from the discussions above that some international students strongly believe that if they do not understand someone's spoken English, there is no sense to continue interaction with them. However, the last student argued that pass of time in Malaysia could help her a lot to learn and get familiar with Malaysian English, and improve her communication with Malaysians.

The participants' perceptions of Malaysian English as a wrong variety are similar to Jenkins' (2009) notion that there is the common perception of a correct and proper variety of English like AmE, while any perceived variations from this would indicate incorrectness (Jenkins, 2009). The respondents' particular perception about Malaysian English also seems consistent with that of Castro et al. (2013) who studied Korean students' attitudes towards Filipino English while taking university courses in the Philippines. Castro found that the Korean respondents were not willing to have English teachers with a Filipino accent; because they worried they would acquire the same accent (Castro et al., 2013).

\section{Conclusion}

The findings obtained from 3 phases of the research in a quantitative-qualitative design show that international students participated in the present had a moderate level of linguistic awareness of Malaysian English and were able to communicate only moderately effectively with Malaysians. It was also revealed that there is a strong correlation between linguistic awareness and intercultural communication effectiveness in a way that when one's linguistic awareness is low, his/her level of uncertainty, mindlessness and anxiety ascends too. This, in result, leads to an increase in intercultural communication ineffectiveness with the host nationals. The results are supported by the qualitative findings obtained from the focus group discussions and autobiographies, in which participants argued how strongly their understanding of Malaysian Enlish has impacted their communication effectiveness with Malaysians. They claimed that it is difficult to understand their accent, localized lexicon, and syntax in Enlish which mostly confuse them. Moreover, it was found that some of the participants were avoiding English interaction with the locals in fear of being affected by the localized variety of English and their English proficiency declines accordingly. In fact, lacking linguistic awareness of Malaysian English, causes one's tolerance level of differences to decrease and mindlessness to increase. This is completely supported by the 36th axiom of the AUM theory which points out that:

Axiom 36: An increase in our knowledge of strangers' languages and/or dialects will produce a decrease in our anxiety and an increase in our ability to predict their behaviour accurately.

Moreover, most respondents maintained that the variety of English spoken by Malaysians is completely different from what they had been taught in schools, and heard in the media, and it was not what they expected as English. The participants mostly compared Malaysian English with the so-called native British and American English varieties in terms of accent, grammar, and localized lexicon used in spoken English which made them confused and disappointed.

Similar results were found by Young (2003) who studied Chinese students' perception of Singaporean English while studying English in Singapore. Upon arriving in Singapore, they felt that Singaporeans should learn British or American English and believed that Singapore English was not a standard, English variety.

The findings are consistent with what was found by Mehdizadeh \& Scott (2005) who focused on international students' adjustment issues, particularly those coming from Iran, when attending university courses in Scotland. They recommended that international students need to attend special language programs to increase their linguistic awareness of Scottish variety of English before moving to Scotland (Mehdizadeh \& Scott, 2005).

Finally, it is concluded that intelligibility of a language variety plays a crucial role in communication effectiveness with the speakers of that variety. Thus, it is recommended that higher education ministries or international universities design 
special courses for international students to familiarize them with the English language variety spoken in the host country. Moreover, ESL and EFL teachers should familiarize students with the diversity of non-native varieties of English around the world, and prepare them to face with the linguistic diversities all around the world, and perceive the differences as specific features of a variation which does not represent deficiency but instead spices that language with specific indigenized markers making it different from all other varieties.

\section{References}

Alavi, M., \& Mansor, S. M. S. (2011). Categories of problems among international students in Universiti Teknologi Malaysia. Procedia-Social and Behavioral Sciences, 30, 1581-1587.

Al-Sharideh, K. A., \& Goe, W. R. (1998). Ethnic communities within the university: An examination of factors influencing the personal adjustment of international students. Research in higher education, 39(6), 699-725.

Anie, A. (1998). English in industry: A study of language choice in two electronics firms in Malaysia. Unpublished PhD dissertation. Kuala Lumpur: Universiti Malaya.

Baskaran, L. (1987). Aspects of Malaysian Syntax. Ph.D Thesis. University of London.

Berger, C.R. \& Calabrese, R. (1975). Some explorations in initial interactions and beyond: Toward a developmental theory of interpersonal communication. Human Communication Research, 1, 99-112.

Bochner, S., McLeod, B. M., \& Lin, A. (1977). Friendship patterns of overseas students: A functional model1. International journal of psychology, 12(4), 277-294.

Bodycott, P., \& Lai, A. (2012). The influence and implications of Chinese culture in the decision to undertake crossborder higher education. Journal of studies in International education, 16(3), 252-270.

Brown, L. \& Holloway, I.(2008). The adjustment journey of international postgraduate students at an English university: An ethnographic study. Journal of Research in International Education. 7 (2): 232-249

Brunton, M., \& Jeffrey, L. (2014). Identifying factors that influence the learner empowerment of international students. International Journal of Intercultural Relations, 43, 321-334.

Castro, M. C. A., \& Roh, T. R. D. G. (2013). The Effect of Language Attitudes on Learner Preferences: A Study on South Koreans' Perceptions of the Philippine English Accent.

Cazden, C. B. (1974). Play and metalinguistic awareness: One dimension of language experience. The Urban Review, 7(1), 28-39.

Crystal, D. (1999). The future of Englishes. English Today, 15(02), 10-20.

Firth, J. R. (1957). Ethnographic analysis and language with reference to Malinowski's views. Man and Culture: an evaluation of the work of Bronislaw Malinowski, 93-118.

Gudykunst, W. (1995). Anxiety/uncertainty management theory. Intercultural communication theory, 8-58.

Gudykunst, W. B. (2005). An anxiety/uncertainty management (AUM) theory of effective communication. Theorizing about intercultural communication, 281-322.

Gumperz, J. J., \& Hernandez-Chavez, E. (1972). Bilingualism, bidialectalism, and classroom interaction. Functions of language in the classroom, 84-108.

Jayasuriya, L., Sang, D., \& Fielding, A. (1992). Ethnicity, immigration and mental illness: A critical review of Australian research: Bureau of Immigration Research.

Jenkins, J. (2009). English as a lingua franca: Interpretations and attitudes. World Englishes, 28(2), 200-207.

Kachru, Braj B. (1992). The other tongue: English across cultures: University of Illinois Press.

Kachru, B. B. (1982). South Asian English. English as a world language, 4.

Kachru, B.B. (1982). The Other Tongue: English Across Cultures. Oxford: Pergamon Press.

Kanno, Y. (2003). Negotiating bilingual and bicultural identities: Japanese returnees betwixt two worlds: Routledge.

Kassing, J. W. (1997). Articulating, antagonizing, and displacing: A model of employee dissent. Communication Studies, 48(4), 311-332.

Kim, Y. (2001). Mapping the domain of intercultural communication: An overview. Communication yearbook, 24, 139158.

Kim, Y. Y. (1988). Communication and cross-cultural adaptation: An integrative theory: Multilingual Matters.

Kitchen, M. (2014). Korean students' stories from an Aotearoa New Zealand high school: perceived affordances of English and Korean language use. Language and Education(ahead-of-print), 1-16.

Khojastehrad, Sh., \& Rafik-Galea, Sh. (Forthcoming). International Students' Attitudes towards Malaysian English Malaysian English Ethnolects.English Language Teaching.

Labov, W. (1972). Sociolinguistic patterns: University of Pennsylvania Press.

Lin, M.-X. (2008). Pragmatic Failure in Intercultural Communication and English Teaching in China. China Media Research, 4(3). 
Long, J.-H., Yan, W.-H., Yang, H.-D., \& Van Oudenhoven, J. P. (2009). Cross-cultural adaptation of Chinese students in the Netherlands. US-China Education Review, 6(9), 1-8.

Lyster, R. (2001). Negotiation of form, recasts, and explicit correction in relation to error types and learner repair in immersion classrooms. Language Learning, 51(s1), 265-301.

Magnusson, E., \& Nauclér, K. (1993). The development of linguistic awareness in language-disordered children. First language, 13(37), 93-111.

Malaklolunthu, S., \& Selan, P. S. (2011). Adjustment problems among international students in Malaysian private higher education institutions. Procedia-Social and Behavioral Sciences, 15, 833-837.

Maundeni, T. (2001). The role of social networks in the adjustment of African students to British society: students' perceptions. Race, Ethnicity and Education, 4(3), 253-276.

McKenzie, R. M. (2006). A quantitative study of the attitudes of Japanese learners towards varieties of English

McKay, S. (2002). Teaching English as an international language. Oxford: Oxford University Press.

Mehdizadeh, N., \& Scott, G. (2005). Adjustment Problems of Iranian International Students in Scotland. International Education Journal, 6(4), 484-493.speech: Aspects of the sociolinguistics of English in Japan. The University of Edinburgh.

Morais, E. (1994). Malaysian business talk: A study of the patterns of conflict and nonconflict in verbal interactions. Unpublished PhD Thesis Submitted to the University of Malaya.

Nair-Venugopal, S. (2006). An interactional model of English in Malaysia: A contextualised response to commodification. Journal of Asian Pacific Communication, 16(1), 51-75

Nair-Venugopal, S. (1997). The sociolinguistics of code and style choice in Malaysian business settings: an ethnographic account. University of Wales. Cardiff.

Neuliep, J. W., \& McCroskey, J. C. (1997). The development of intercultural and interethnic communication apprehension scales. Communication Research Reports, 14(2), 145-156.

Pillai, S., Mohd Don, Z., Knowles, G., \& Tang, J. (2010). Malaysian English: An instrumental analysis of vowel contrasts. World Englishes, 29(2), 159-172.

Ouarasse, O. A., \& van de Vijver, F. J. (2005). The role of demographic variables and acculturation attitudes in predicting sociocultural and psychological adaptation in Moroccans in the Netherlands. International Journal of Intercultural Relations, 29(3), 251-272.

Redmond, M. V., \& Bunyi, J. M. (1993). The relationship of intercultural communication competence with stress and the handling of stress as reported by international students. International Journal of Intercultural Relations, 17(2), 235254.

Sapir, E. (1931). The function of an international auxiliary language: International Auxiliary Language Association.

Seim, B. (2008). The Perception of Arab-Accented Speech by American Native Speakers and Non-Native Speakers from East and South-East Asia. Paper presented at the Perspectives on Arabic Linguistics XXI: Papers from the Twenty-First Annual Symposium on Arabic Linguistics, Provo, Utah, March 2007.

Sharifian, F. (forthcoming). Glocalization of English in World Englishes: An emerging variety among Persian speakers of English'. In M. Saxena and T. Omoniyi (Eds), Contending with globalization in World Englishes. Bristol, UK: Multilingual Matters.

Siegler, R. S. (1985). Encoding and the development of problem solving. In J. Chipman, W. Segal, \& R. Glaser (Eds.), Thinking and learning skills: Research andopen questions (Vol. 2) (pp. 161-185). Hillsdale, NJ: Lawrence Erlbaum Associates.

Spencer-Rodgers, J., \& McGovern, T. (2002). Attitudes toward the culturally different: The role of intercultural communication barriers, affective responses, consensual stereotypes, and perceived threat. International Journal of Intercultural Relations, 26(6), 609-631.

Strevens, P. (1977). New Orientations in the teaching of English. London: Oxford University Press.

Ward, C., \& Searle, W. (1991). The impact of value discrepancies and cultural identity on psychological and sociocultural adjustment of sojourners. International Journal of Intercultural Relations, 15(2), 209-224.

Webb, N.M., M.L. Franke, J. Ing, J. Wong, C.H. Fernandez, and A.C. Turrou. (2014). "Engaging with Others' Mathematical Ideas: Interrelationships among Student Participation, Teachers' Instructional Practices, and Learning.". International Journal of Educational Research, 63, 79-93.

Yashima, T., Zenuk-Nishide, L., \& Shimizu, K. (2004). The influence of attitudes and affect on willingness to communicate and second language communication. Language Learning, 54(1), 119-152

Young, C., \& Yee, M. (2006). Macao students' attitudes toward English: a post-1999 survey. World Englishes, 25(3-4), 479-490. 